\title{
Design of English Multimedia Teaching System Based on Diversification Theory
}

\author{
https://doi.org/10.3991/ijet.v12i01.6488 \\ Minsheng Lou \\ Jinhua Polytechinc, Jinhua, China \\ 3545865370 @qq. com
}

\begin{abstract}
Based on the diversification theory, this paper designed a multimedia technology-based English teaching system framework which is used to assist English teaching in classroom. The whole system framework consists of two parts: the part of learning resource allocation and the part of English teaching activities. Learning resource allocation is mainly to expand English learning materials from the traditional printed resources to audios, videos, animations and other forms of resources; the use of multimedia resources for teaching activities is achieved mainly through the English speech teaching and lecturing device designed with the function of playing multimedia files. In order to test the application effect of multimedia technology in English teaching, this paper chose the public course of "Vocational English" as the experimental content, and compared the effect of respectively using multimedia technology to teach freshmen of Grade 2016 and adopting the traditional teaching method to teach students of Grade 2015. The outcome shows that the use of multimedia technology in English teaching can improve students' interest in learning, reduce their pressure of learning English, and enhance their sense of accomplishment in learning, indicating that multimedia-assisted teaching can effectively improve English teaching results.
\end{abstract}

Keywords-Multimedia technology, English teaching, speech playback, diversification

\section{Introduction}

As an important means assisting modern educational technology, multimedia technology can be used to set personalized learning programs according to the user's individual needs, so as to achieve personalized learning and individual needs-driven discovery learning. The application of multimedia technology into English learning can give full play to its advantages in collection of different types of media information and fully mobilize the participation of students in learning; multimedia information technology contains a large amount of information of various types, and there- 
fore can achieve fast and intuitive transmission of massive knowledge [1]. Since the 20th century, multimedia technology has begun to be applied to education and teaching. Gradually, foreign language teaching has also started to introduce multimedia technology-based auditory and visual media to actively mobilize the senses of learners and to improve the efficiency of information reception. Later, with the development of computer and network technology, the advantages of multimedia technology become increasingly prominent in foreign language learning, especially in listening and speaking. These strengths have contributed to the wider spread and application of multimedia technology both at home and abroad [2].

\section{Review of Research Progress}

Azuma (2010) proposed that instructors can utilize synthesized English speech generated by commercial TTS engines within Moodle-based e-Learning environments, or CALL room environments, as well as the normal classroom environment when teaching English as a foreign language. TTS synthesized speech materials have been argued to be able to significantly reduce costs for teaching materials and expand the horizons of foreign language teaching [3]. Since 2010, the online-learning platform Moodle has been tested by the department for German language and linguistics at the Hacettepe University, Ankara, and found to have the function of successfully enriching its course system. It is easier and more effective to distribute information via Moodle, which is an online support for communication technology. Turkey and its higher education system (especially foreign language) have been suggested to avoid permanent utilization of traditional methodologies (such as grammar translation method) and to adopt blended learning. The article reflects barriers and difficulties for the performance of blended learning at the department for German language and linguistic at the Hacettepe University, while presenting and proving the corresponding way for foreign language learning at the same time [4]. According to multimedia theory and theories of selective attention, Ji Yue et al. (2013) explored audiovisual interference in the presentation of foreign language teaching information from the perspective of learners' cognition. In the study, it is argued that the presentation of classroom teaching information must take into account the cognitive processing of learners. Excessive or mismatched audiovisual information is not conducive to effective processing in working memory, but causes interference. The use of this finding has achieved certain teaching effects [5]. Chen Dongchun (2011) proposed the application of economic principles of language in multimedia teaching of foreign languages, mainly reflected in the form of multimedia courseware and simplicity of the structure, to minimize the pressure on students and reduce teachers' oral teaching time [6]. Liu Shuying et al. (2011) were guided by the 4C/ID overall task design pattern created by Merrienboer, consisting of identifying learning tasks, searching supportive information, providing instant information, and designing some task exercises, and followed instructional principles of the learning theory of constructivism and the theory of situated cognition, to explore the design of English class multimedia courseware with the assistance of specific power point lessons. At the same time, the 
involvement of the designed courseware in English teaching were favored by students and highly evaluated by teachers [7].

"Vocational English" is a basic public course in higher vocational education, but traditional English textbooks are outdated and not close to reality, making it difficult to arouse students' high enthusiasm for classroom learning [8]; the traditional English teaching process is mostly the standardized classroom teaching mode which cannot meet the learning needs of students at all levels and also results in the impossibility to obtain desired educational performance [9]; besides, schools have more local teachers and relatively fewer professional foreign teachers, and different teachers have their personal characteristics in English pronunciation, meaning that students need to adapt to different accents and contributing to more learning difficulties. On this basis, this paper designed a multimedia technology-based English teaching system, hoping to overcome the problems above. The innovation of the system was achieved by designing diversified multimedia learning resources equipped with video and audio learning materials with standard pronunciation of native English speakers to solve the aforementioned problems. Students can follow the teaching speech materials with standard pronunciation in the process of learning, correct their wrong pronunciation and inappropriate speed of oral speaking, avoid the learning difficulties caused by different accent characteristics, and improve their listening level through listening to audio materials. Secondly, the system offers a new English multimedia database. According to the database setting, students can choose pronunciation following, word memorization and situational conversation, or choose English background music and English video in line with their individual tastes.

\section{Theoretical Basis}

Diversified teaching refers the application of a targeted, flexible and comprehensive teaching approach at different stages of the teaching level through the integration of various media teaching methods and individual differences to realize the combination of unified instruction teaching and modern traditional teaching [10]. The application of diversification theory in multimedia teaching means the use of modern teaching instruments and equipment (such as cameras, video recorders, projectors, slides, tape recorders, etc.) and the optimized combination of a variety of teaching methods to fully mobilize students' visual, auditory, tactile, kinesthetic and other body organs and to improve their efficiency of receiving information and giving out information, so that this integrated teaching system can acquire organic integration of perception, thinking, practice and all other links. It is a systematic, multi-level, and mutually integrated network system which is conducive to achieving teaching objectives. In the teaching process, it can be used to deal with the actual situation, make full use of a variety of equipment and devices to enrich the teaching methods, and to complete the expected teaching results more efficiently.

There are four teaching phases in foreign language teaching under the guidance of diversification theory: (1) the perception of ability: to activate the various intelligences through touching, smelling, tasting, seeing and other sensual experience 
and obtain perceptual understanding of various features of the surrounding world; (2) the communication of ability: to experience emotions and adjust and strengthen cognition activities through contacting with other people, things, or specific situations; (3) the teaching of ability: to convey learning methods and strategies in teaching, link intellectual development and teaching focus, and help students understand their own intelligence level and explore their potential; (4) the integrated use of ability: to promote students; integrated use of a variety of intelligences through evaluation, so that each student can learn confidently and make a difference [11].

The multimedia courseware making course is quite practical. Practice teaching and implementation is an important part of course teaching, and has a great influence on the realization of training objectives of the course. In the teaching reform, flexible and scientific diversified teaching reform measures as well as diversified practice competition platform construction are mainly adopted to explore the application of the learning theory of constructivism in the new curriculum system. In addition, the platform designed should focus on cultivating students' ability to obtain resources through the network, self-learning competence and enthusiasm, place emphasis on the role of project-driven factors, practice platform, competition platform and interest groups in promoting throughout teaching of the course, and guide students to establish correct goals of courseware production and achieve efficient completion of production, so as to reach the goal of training practical talents and to improve the overall quality of higher vocational education. The specific structure is shown in Figure 1.

\section{$4 \quad$ Framework Design of Diversified Multimedia English Teaching System}

Based on diversification theory, this paper designed the system framework of applying multimedia technology to English teaching, as shown in Figure 1. The framework is composed of two parts: 1) the part of learning resource allocation, mainly to select and download audio-visual media learning materials in a variety of formats, including audio vocabulary materials with standard English pronunciation of native English speakers, selected English songs, short English videos, English audio books and other reading materials; 2) the part of multimedia technology-based English teaching activities, mainly to use a variety of audio and video materials equipped in the system for English teaching, including following and learning the basic pronunciation, broadcasting English words and sentences, conversation practice in animated situations, music video playback and so on. They are primarily done by the English speech teaching and lecturing device designed with the function of playing multimedia files. The application framework is given in Figure 2.

\subsection{Allocation of English learning resource in a diversified environment}

In a diversified environment, learning resources that can be used for English learning are no longer limited to traditional textual and pictorial information or to 
traditional media such as newspapers and books. Multimedia technology can expand the content of resources applied to English learning to various audio and video materials, and then classify these resources in accordance with their form and content respectively. In the teaching process, teachers can choose the required resources for teaching according to the teaching objectives.

Due to the diversification of multimedia learning resources, teachers can not only select appropriate learning materials according to the actual teaching objectives of each lesson, but also provide students with different learning bases with different forms and types of learning resources according to their actual learning situation, so that they can break limitations brought by the modularization of fixed or unified teaching methods. Figure 3 shows types of multimedia resources in the learning resource library.

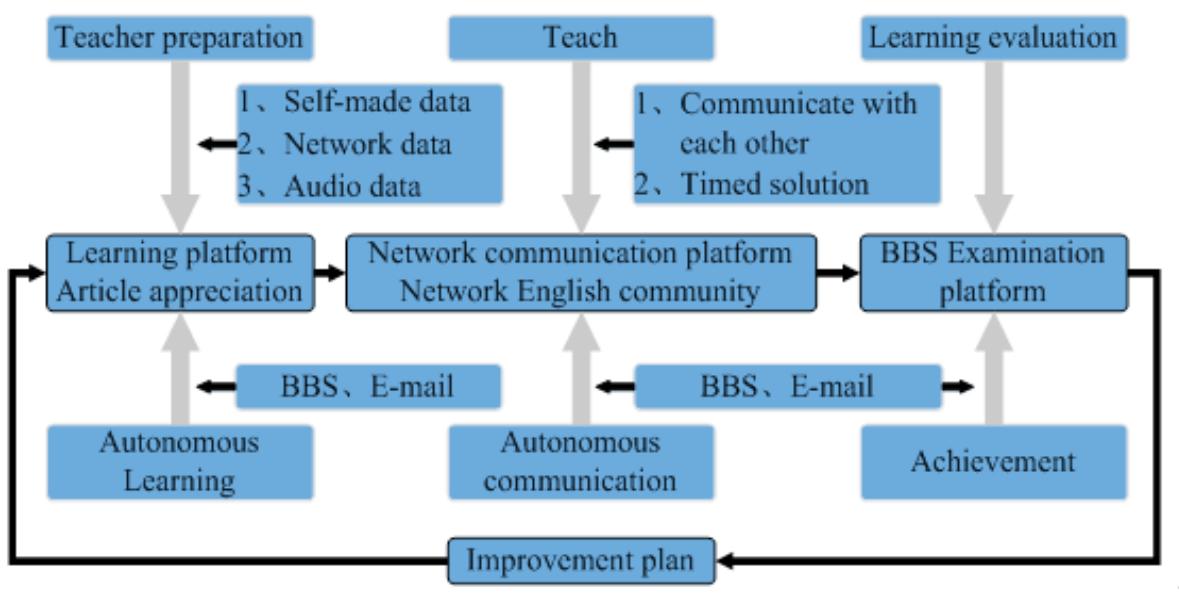

Fig. 1. Structure of the method of diversified teaching

Piano teaching exchange platform based on WeChat
\begin{tabular}{|l|l|}
\hline Configure learning \\
1、Standard vocabulary pronunciation \\
2、English music & English teaching activities \\
3、English short film & 2、 Vocabulary memory \\
4、Audiobook & 3、Scene conversation \\
\hline
\end{tabular}

Fig. 2. Framework of the multimedia technology English teaching application system 


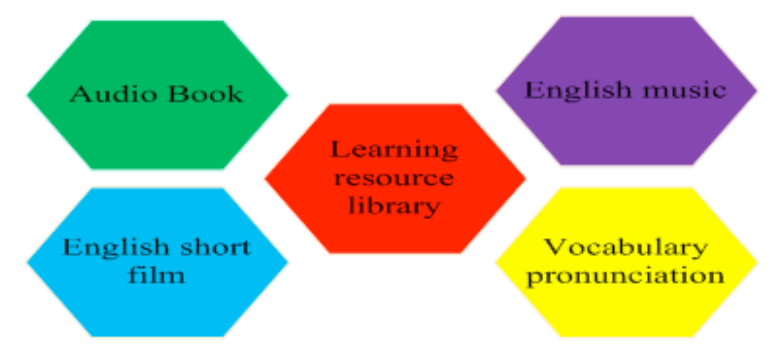

Fig. 3. Types of multimedia resources in the learning resource library

\subsection{Design of the English speech teaching and lecturing device with the function of playing multimedia files}

English teaching includes a variety of learning contents, such as basic vocabulary, oral pronunciation, dialogue application, etc. In particular, English learning requires students to master the standard pronunciation and tone, and flexibly apply the words they have learned to dialogues. In other words, students need the opportunity to contact the Standard English pronunciation and engage in corresponding oral practice in the learning process. At the same time, in order to overcome the problems of low enthusiasm and huge learning difficulties in traditional teaching, this paper designed a set of English speech teaching and lecturing device with the function of playing multimedia file, to correct students' pronunciation through broadcasting the standard electronic pronunciation. In addition, the audio and video resources configured in the multimedia library can be employed to adjust the teaching atmosphere and improve the teaching effectiveness. The specific structure is shown in Figure 4.

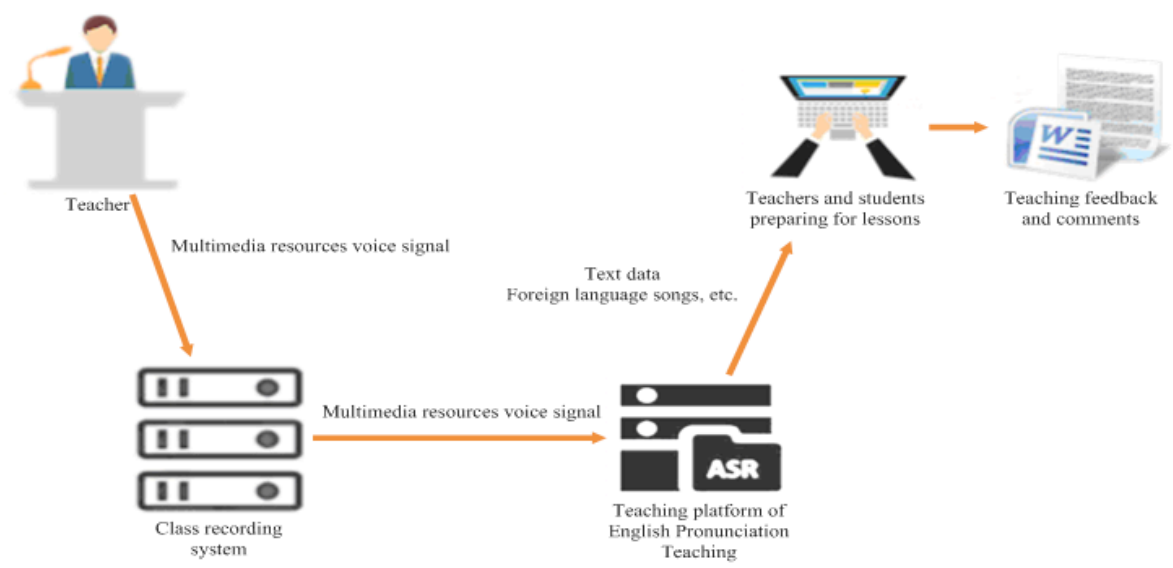

Fig. 4. Structure of the English speech teaching and lecturing device with the function of playing multimedia file 
The whole system of the device determines whether the sliding board blocks the corresponding English speech and its corresponding switch through setting the state of the elastic rubber band; different English speech functions are selected via the button switch. Then, the selected speech is pronounced and explained by the speaker which is controlled by the microprocessor, to achieve self-help speech teaching.

\subsection{Function design of Diversified Multimedia English Teaching System}

The overall function design of the diversified multimedia technology based English teaching application system is shown in Figure 5:

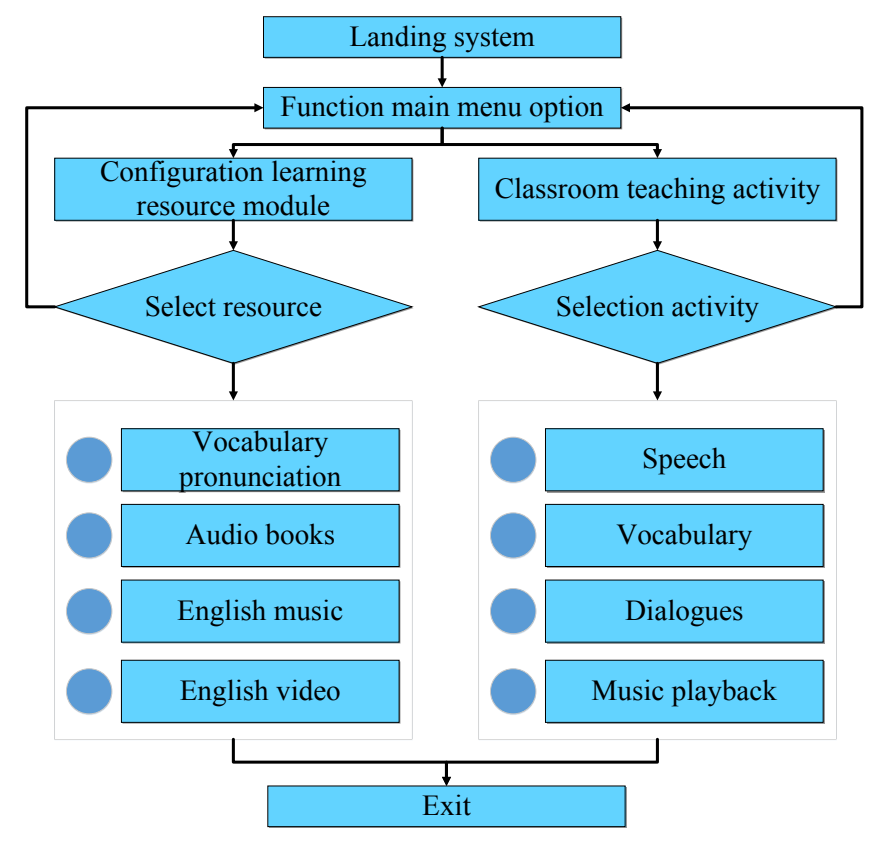

Fig. 5. Overall function design of the English teaching application system

(1) The system limits the user's permissions. The user who wants to log on and use the system needs to enter a valid account and the corresponding password.

(2) After logging on the system with a valid account and password, the user can enter the main function menu of the system. The main function of this application framework consists of two parts: the module of learning resource allocation and the sub-module of selecting teaching activities.

(3) After selecting the submenu of learning resource allocation from the main menu, the user can enter module of learning resource allocation. This module is primarily to achieve the downloading of various forms of multimedia resources in English teaching activities, to form a systematic multimedia learning resource database. The interface is given in Figure 6. 


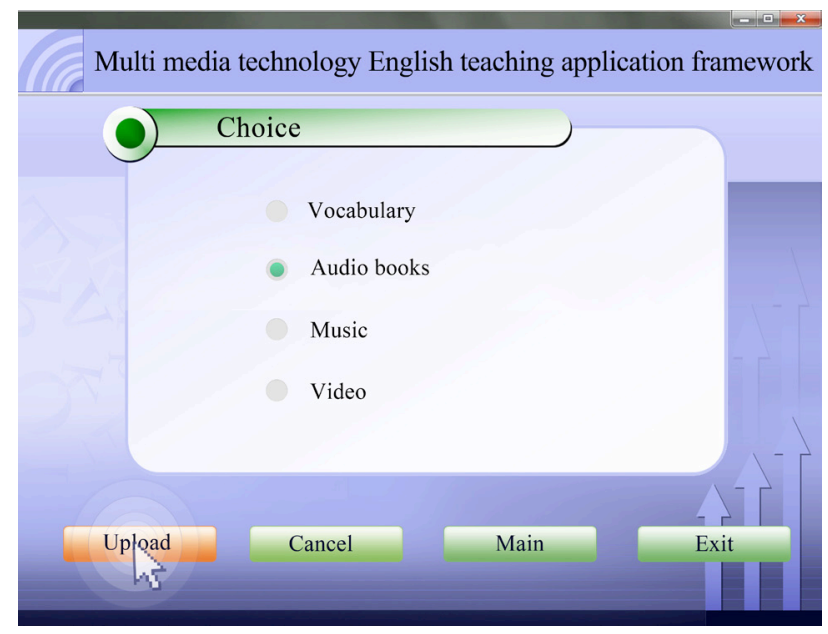

Fig. 6. Interface of the submenu of learning resource allocation

(4) After clicking the submenu of selecting teaching activities in the main menu and select the OK button, the user will enter the module of selecting teaching activities. This module is mainly used for the implementation of English teaching activities. If pronunciation following is chosen, the user can follow the pronunciation of words, sentences, and articles given by the system to have the practice of pronunciation following; if word memorization is select, the user will get access to recitation and test of the vocabulary learned; situational conversation enables the user to learn spoken dialogues according to the animated situations provided by the system; music playing which can play the appropriate music or video will improve learning passion and enthusiasm, and increase learning efficiency. Through select the main menu button, the user can return to the main menu of the system and re-select the function module.

\section{Test of Platform Effect}

This paper designed a comparative experiment to study the effect of applying the multimedia speech playing device-based system in English teaching. The vocational course of "Vocational English" for higher vocational students in Jinhua Polylechnic, Zhejiang, China, was selected as the experiment course. While freshmen of Grade 2016 taught by multimedia teaching technology were the experimental group, students of Grade 2015 who adopted the traditional teaching method were the control group. 180 students were randomly selected from the corresponding grade. They were involved in questionnaire survey to investigate and analyze two typical learning contents, namely, word recitation and oral communication. In the survey, degree of learning interest in the learning process, intensity of learning pressure and individual sense of accomplishment were taken as the evaluation indicators. The score of each indicator ranges from 0 to 100 points. Higher score means that the degree is also higher. The survey data are as table 1 . 
Paper-Design of English Multimedia Teaching System Based on Diversification Theory

Table 1. Data regarding degree of students' English learning interest, intensity of pressure and sense of accomplishment

\begin{tabular}{ccccccc}
\hline \multirow{2}{*}{ Grade } & \multicolumn{3}{c}{ Word recitation test } & \multicolumn{3}{c}{ Oral communication test } \\
& $\begin{array}{c}\text { Degree of } \\
\text { interest }\end{array}$ & $\begin{array}{c}\text { Intensity of } \\
\text { pressure }\end{array}$ & $\begin{array}{c}\text { Sense of accom- } \\
\text { plishment }\end{array}$ & $\begin{array}{c}\text { Degree of } \\
\text { interest }\end{array}$ & $\begin{array}{c}\text { Intensity of } \\
\text { pressure }\end{array}$ & $\begin{array}{c}\text { Sense of accom- } \\
\text { plishment }\end{array}$ \\
\hline 2016 & $85.7 \pm 12.1$ & $73.2 \pm 14.4$ & $85.1 \pm 11.7$ & $83.5 \pm 12.2$ & $78.1 \pm 14.6$ & $84.2 \pm 13.9$ \\
2015 & $82.9 \pm 15.7$ & $77.6 \pm 18.7$ & $81.2 \pm 13.9$ & $81.3 \pm 14.1$ & $82.7 \pm 17.3$ & $77.6 \pm 15.9$ \\
\hline
\end{tabular}

As can be seen from the table, the use of multimedia technology can bring a variety of learning methods into teaching activities. Students' interest in learning will be excited out, and even show a significant upward trend. Meanwhile, their active participation in learning will promote the absorption of knowledge and understanding, so as to enhance the sense of academic accomplishment brought by acquisition of knowledge. There is a negative relationship between the score of learning pressure and the degree of interest. Students' learning pressure will drop slightly with the increase of learning interest and the rise of individual sense of accomplishment. In addition, regardless of basic word recitation or oral practice, the improvement of interest keeps a positive relationship with the sense of accomplishment. It shows that the integration of diversified multimedia technology into teaching activities can enhance students' degree of attention to the course and stimulate more enthusiasm for English learning.

\section{Conclusion}

This paper studied the effect of applying multimedia technology in English teaching, designed a systematic framework for using diversified multimedia materials in English teaching, and conducted a comparative experiment to explore its difference with traditional teaching. The experimental result shows that the utilization of multimedia technology in English teaching can enhance students' enthusiasm for learning, improve their attitude towards English learning and promote their academic performance. The reasons can be analyzed from the following aspects: firstly, in the process of foreign language multimedia teaching designed in this paper based on diversification theory, more attention is paid to the autonomy and individuation of students' individual learning, regard students as the center and respect individual differences among students. Students can choose English lessons and English exercises at an appropriate level according to their level of English proficiency, thus indirectly reducing their learning pressure and improve their interest in learning. Secondly, diversification theory is based on the interactive cooperative learning model, in which students are no longer passive under the authorized command of teachers. The whole learning process is quite open, allowing teachers and students to continue their communication which each other. For example, in the multimedia network classroom, teachers and students can freely swift between two communications, including online communication and face-to-face communication, at all times. Translation learning on the Internet is carried out entirely in the virtual space. This long-distance communication greatly 
broadens the scope of the members involved in communication, so that it is possible to broaden students' horizons, expand their breadth of understanding and thought, and stimulate their interest in learning, thereby increasing their sense of accomplishment. Moreover, this system was developed on the basis diversified multimedia design, not only to provide video and audio learning materials with the standard pronunciation in the classroom, and but also offer a variety of interesting English learning resources, such as English music, short English stories, etc. They are quite effective in assisting students in learning and teachers in teaching.

\section{$7 \quad$ References}

1. Ganesan, R., \& Chandramohan, V.G. "Use Of Multimedia In Teaching English As A Foreign/Second Language," Asian Journal of Research in Social Sciences and Humanities, vol. 6, no. 6, pp. 2416-2420, January 2016. https://doi.org/10.5958/22497315.2016.00373.7

2. Kramsch, C. "Culture in foreign language teaching," Iranian Journal of Language Teaching Research, vol. 1, no. 1, pp. 57-78, January 2013.

3. Azuma, J. "Impact of TTS Technology on Foreign Language Teaching: New Horizons of Multimedia Teaching Material Development," Journal of the Center for Research \& Development in Higher Education University of Marketing \& Distribution Sciences, no. 6, pp. 1-11, June 2010.

4. Hertsch, M.F. "Multimedia-Based Enrichment for Foreign Language Teaching," ProcediaSocial and Behavioral Sciences, vol. 70, pp. 615-621, January 2013. https://doi.org/10.1016/j.sbspro.2013.01.100

5. Ji, Y., Shi, L. "The Audio and Visual Interference in Instructional Presentation in Multimedia-based Foreign Language Classes," Computer-Assisted Foreign Language Education in China, no. 2, pp. 41-46, June 2013.

6. Chen, D.C. "Economy Principle in the Multi-Media-Based Foreign Language Teaching," Modern Educational Technology, vol. 21, no. 7, pp. 61-63, July 2011.

7. Liu, S.Y., Zhang, Z.H. "Study on the Design of Foreign Language Multimedia Courseware Based on 4C/ID Integrative Design Model - Case Study of A Design of Power Point Teaching Courseware," Journal of Mudanjiang University, no. 4, pp. 155-157, April 2011.

8. Wei, J. "The Concept of Building Foreign Language Learners' Individual Ecological Environment in the Multimedia Network Environment," Computer-Assisted Foreign Language Education in China, no. 6, pp. 69-76, December 2010.

9. Kramsch, C., \& Andersen, R.W. "Teaching text and context through multimedia," Language Learning \& Technology, vol. 2, no. 2, pp. 31-42, January 1999.

10. Jarrow, R.A., Lando, D., Yu, F. "Default Risk and Diversification: Theory and Applications," Mathematical Finance, vol. 15, no. 1, pp. 1-26, January 2011. https://doi.org/10.1111/j.0960-1627.2005.00208.x

11. Chen, Z. "The Reform of English Teaching Situation and Practice of University Based on the Theory of Constructivism," Open Cybernetics \& Systemics Journal, vol. 9, no. 1, pp. 2576-2581, January 2015. https://doi.org/10.2174/1874110X01509012576 
Paper-Design of English Multimedia Teaching System Based on Diversification Theory

\section{Author}

Minsheng Lou is a Lecturer of Jinhua Polytechinc, Jinhua 321007, China. His research interests include English Teaching and Multimedia teaching system. (3545865370@qq.com)

Submitted 03 December 2016. Published as resubmitted by the author 20 January 2017. 